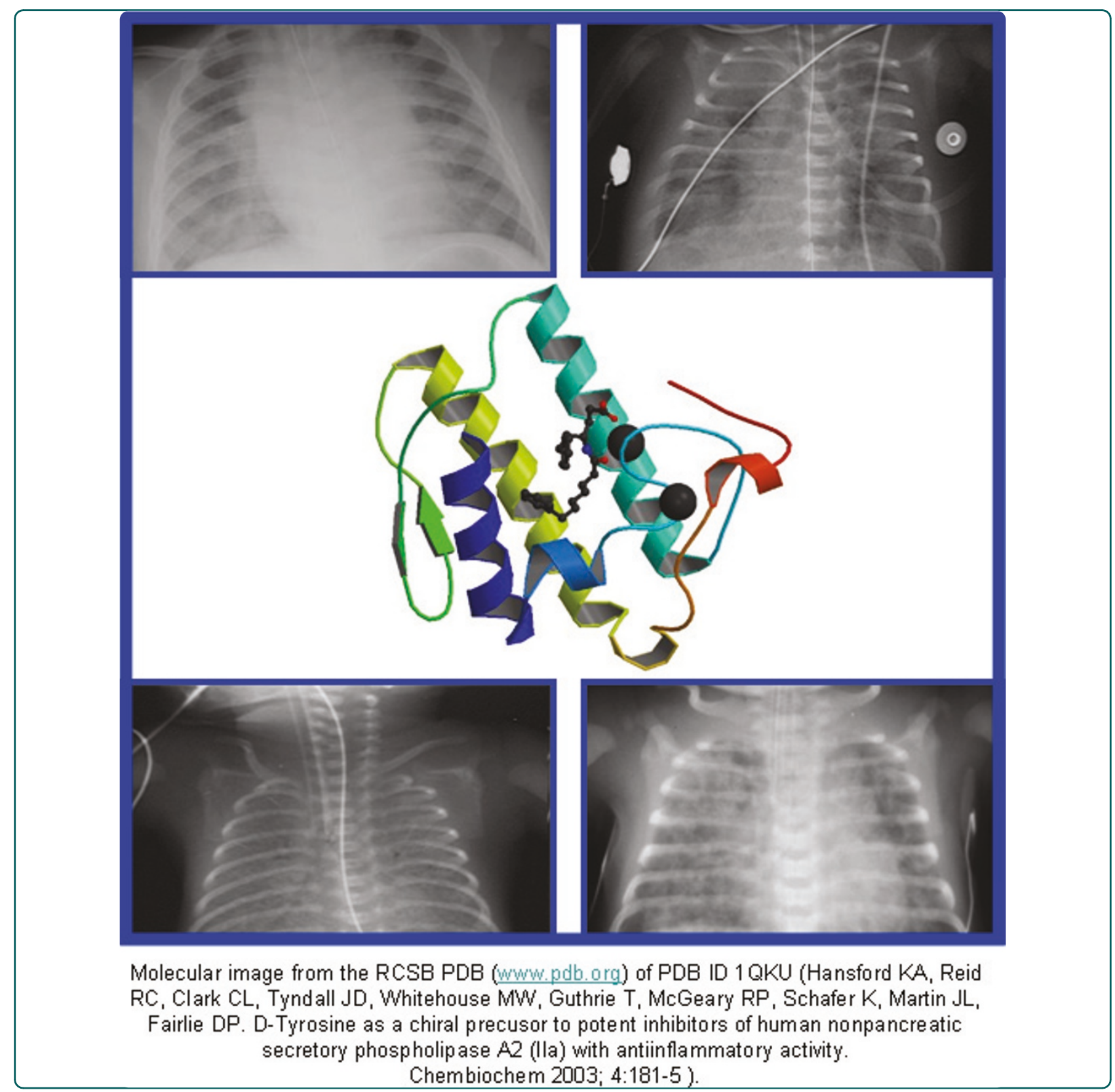

\title{
Secretory phospholipase A2 pathway in various types of lung injury in neonates and infants: a multicentre translational study
}

De Luca et al. 


\title{
Secretory phospholipase A2 pathway in various types of lung injury in neonates and infants: a multicentre translational study
}

\author{
Daniele De Luca ${ }^{1,2^{*}}$, Ettore Capoluongo ${ }^{1}$ and Vincent Rigo ${ }^{3}$, for \\ the Study group on Secretory Phospholipase in Paediatrics (SSPP)
}

\begin{abstract}
Background: Secretory phospholipase A2 (sPLA2) is a group of enzymes involved in lung tissue inflammation and surfactant catabolism. sPLA2 plays a role in adults affected by acute lung injury and seems a promising therapeutic target. Preliminary data allow foreseeing the importance of such enzyme in some critical respiratory diseases in neonates and infants, as well. Our study aim is to clarify the role of sPLA2 and its modulators in the pathogenesis and clinical severity of hyaline membrane disease, infection related respiratory failure, meconium aspiration syndrome and acute respiratory distress syndrome. SPLA2 genes will also be sequenced and possible genetic involvement will be analysed.
\end{abstract}

Methods/Design: Multicentre, international, translational study, including several paediatric and neonatal intensive care units and one coordinating laboratory. Babies affected by the above mentioned conditions will be enrolled: broncho-alveolar lavage fluid, serum and whole blood will be obtained at definite time-points during the disease course. Several clinical, respiratory and outcome data will be recorded. Laboratory researchers who perform the bench part of the study will be blinded to the clinical data.

Discussion: This study, thanks to its multicenter design, will clarify the role(s) of sPLA2 and its pathway in these diseases: sPLA2 might be the crossroad between inflammation and surfactant dysfunction. This may represent a crucial target for new anti-inflammatory therapies but also a novel approach to protect surfactant or spare it, improving alveolar stability, lung mechanics and gas exchange.

\section{Background}

\section{Phospholipase A2 biology}

Phospholipases A2 are a widely distributed group of enzymes primarily implicated in the turnover of membrane phospholipids and lipid digestion. They are also crucial for the inflammation pathways, as they are the first step for the production of eicosanoids and other inflammatory mediators $[1,2]$. Secretory phospholipase A2 (sPLA2) is the low molecular, well conserved and secreted form of the enzyme. It is excreted into the alveoli mainly by macrophages and mast cells [1-3]. sPLA2 has a dual role, as it contributes to the

\footnotetext{
* Correspondence: dm.deluca@fastwebnet.it

${ }^{1}$ Pediatric Intensive Care Unit, Dept of Emergency and Intensive Care, University Hospital "A.Gemelli", Catholic University of the Sacred Heart Rome, Italy

Full list of author information is available at the end of the article
}

inflammation pathway and it is also the main enzyme involved in the catabolism of surfactant $[1,2,4]$ This complex proteo-lipid mixture is essential for the alveolar opening and the maintenance of an adequate gas exchange.

sPLA2 is well known to be involved in lung inflammation and surfactant degradation based on animal and human studies in adults [4]. Therefore, it is conceivable that SPLA2 through either its pro-inflammatory role or the surfactant catabolism, might be involved in the pathogenesis of several critical respiratory diseases. Basic data have shown that both sPLA2 activity and expression are regulated by many factors including steroids, Clara Cell Secretory Protein (CCSP), Tumor Necrosis Factor- $\alpha$ (TNF $\alpha)$, Surfactant protein A (SP-A) and certain surfactant phospholipids, Interleukine-1 (IL-1) and some other cytokines [4]. 
Imbalance in the sPLA2 pathway due to different production of its modulators may account for increased surfactant degradation or lung tissue inflammation. Schematic representation of sPLA2 pathway is presented in Figure 1: the possible roles of the enzyme in the pathogenesis of acute respiratory distress syndrome (ARDS), infant respiratory distress syndrome (iRDS), broncho-pulmonary dysplasia (BPD), infection related respiratory failure (IRRF) and meconium aspiration syndrome (MAS) are also illustrated. Data about the sPLA2

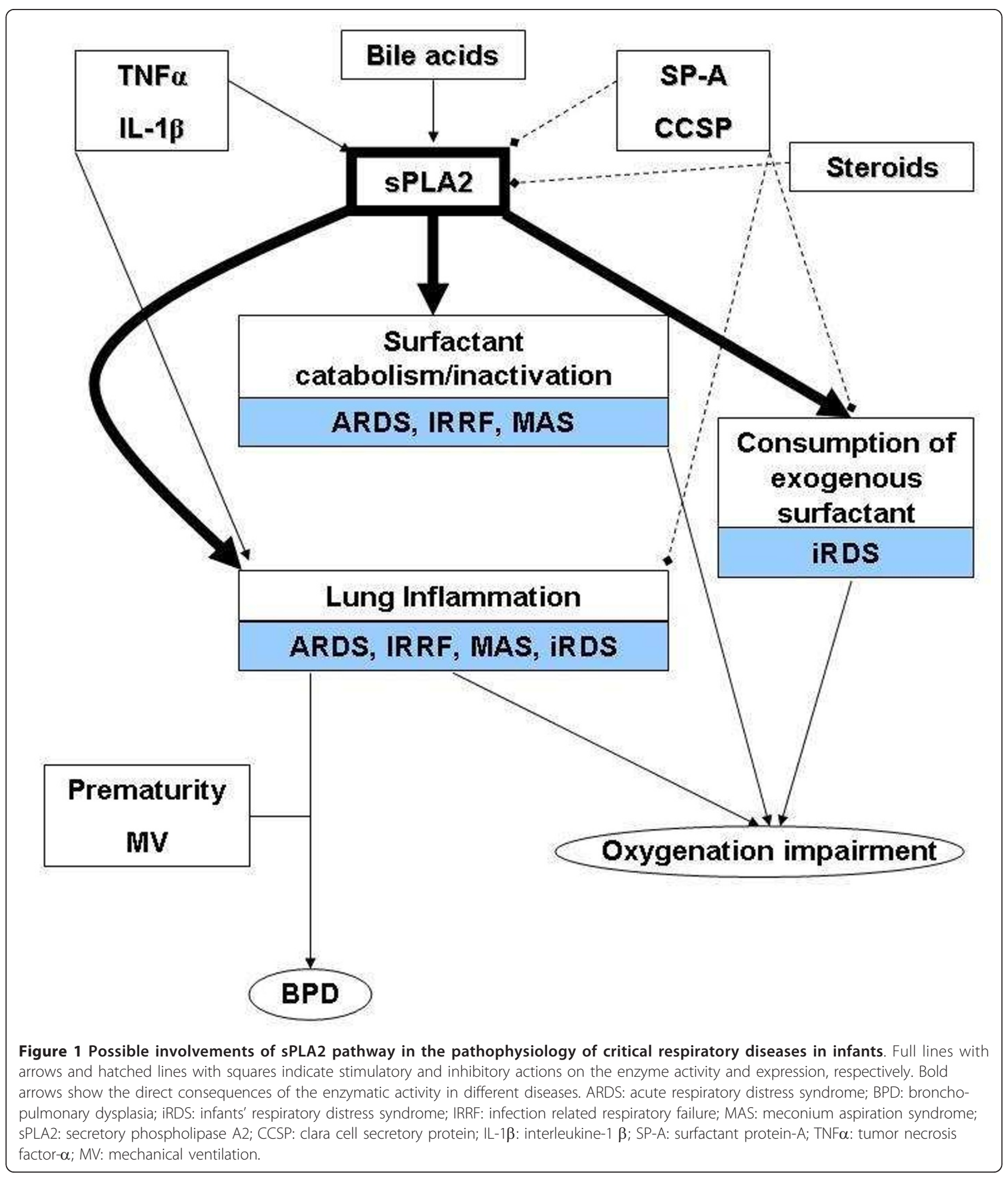


role in each of the above-mentioned diseases are described in the following paragraphs.

\section{sPLA2 and ARDS}

A wide body of literature suggests a role for sPLA2 in the development of ARDS and acute lung injury (ALI), its milder form. sPLA2 interferes with the surfactant activity and so reduces compliance [4-6]. sPLA2 starts a vicious cycle in which it damages the surfactant; since some surfactant components have their own inhibitory effect on sPLA2 activity and expression $[7,8]$, the sPLA2-induced surfactant damage reduces this inhibition and thus the enzyme is able to further catabolize the surfactant phospholipids [4]. Thus, sPLA2 facilitates the action of other injurious agents against the lung epithelium, leading to further surfactant damage, alveolar collapse and respiratory impairment [4]. This process is also linked to the lung tissue inflammation, since TNF $\alpha$ and some other pro-inflammatory cytokines are strong sPLA2 inductors throughout the regulation of NFkB nuclear transcription factor $[4,7,8]$. Moreover, sPLA2 itself starts the inflammatory cascade, since it is the first step in the biochemical pathway leading to the production of arachidonic acid derivatives [9]. Inflammation may further inactivate surfactant, contributing to the above-described vicious cycle [4-6]. sPLA2 activity is raised in broncho-alveolar lavage fluid (BALF) in animal models of ARDS and in adult patients and this correlates with the clinical severity and mortality $[4,5,8,10]$. We recently found raised enzyme levels in post-neonatal ARDS, similarly to the adult findings [11]. Moreover, respiratory syncytial virus (RSV) infection seems to cause a more severe ARDS because of the sPLA2 overexpression, triggered by the RSV itself [12]. Consistently, transgenic animals defective for the CCSP gene, experience higher inflammation and mucous production, when infected by RSV [13].

In animal models, the administration of sPLA2 inhibitors reduced lung inflammation and improved both compliance and oxygenation, especially if the inhibitor is administered early during the injury development $[8,14]$. Similarly, the inhibitor was able to reduce sPLA2 activity in BALF of patients with iRDS, IRRF, MAS and postneonatal ARDS [15].

\section{sPLA2 and iRDS}

The importance of surfactant is well known in neonatal critical care. An inadequate surfactant production is the pivotal cause of hyaline membrane disease, also called infant respiratory distress syndrome (iRDS), the most frequent respiratory disease of preterm infants [16]. Although exogenous surfactant administration is curative in many preterm infants, long-term respiratory sequels are still a significant problem in this population, with $20 \%$ of the surviving preterm babies affected by BPD [17]. Moreover, the tiniest babies born at the limit of viability often require multiple surfactant administrations. Many of these very preterm deliveries are associated with infections and chorioamnionitis [18]. In these cases, inflammation lengthens the lung injury, decreasing the usefulness of exogenous surfactant and damaging the lung tissue [18]. In such situation, sPLA2 is likely to play a crucial role: we found increased sPLA2 levels in babies with iRDS comparing to normal term neonates [19]. sPLA2 was found to increase foetal neutrophil migration and so to enhance lung tissue inflammation [20]. Babies with higher sPLA2 activity are likely to be the ones needing repeated surfactant administrations and they are at higher risk for chronic lung disease.

Some authors recently tried to administer CCSP to preterm neonates. CCSP is a natural inhibitor of sPLA2 in the lung $[21,22]$. This drug has been given endotracheally together with surfactant [21] achieving a significant reduction in lung tissue inflammation. Similar results in terms of inflammatory markers and lung function have been obtained in animal models of iRDS and MAS [23-25].

Other authors have proposed the same approach with endotracheally administered budesonide, vehicled by surfactant [26]. Budesonide inhibits SPLA2 and has been associated with a decrease in the release of sPLA2induced pro-inflammatory cytokines [27]. Surfactant is the cornerstone of iRDS therapy and the sPLA2 inhibition could theoretically protect it, reducing the need for repeated doses and improving the long-term respiratory outcome.

\section{sPLA2 and IRRF}

During sepsis or pneumonia surfactant may be inadequately produced and recycled or it may be inactivated by lung tissue inflammation $[28,29]$. In these cases surfactant therapy is often less useful and does not achieve the clinical improvement usually seen in iRDS $[28,29]$. Mortality rate for such condition is still remarkable in term infants and even higher in preterm babies, who often experience sepsis or pneumonia as nosocomial infections acquired in the intensive care units [16]. sPLA2 is raised in BALF of neonates with IRRF [19]. This is consistent with animal and cellular studies showing that bacterial membrane lipopolysaccharide is a potent inductor of sPLA2 [4]. Nonetheless, no definite data are available about the role of sPLA2 and its pathway during IRRF.

\section{sPLA2 and MAS}

Pancreatic sPLA2 has been indicated as a main etiological agent of MAS, one of the worst form of neonatal 
lung injury, characterized by massive surfactant inactivation, lung tissue inflammation and airway obstruction [30-32]. Meconium carries high amounts of sPLA2 and bile acids that are likely to contribute to lung injury, increasing sPLA2 activity and causing further surfactant inactivation [33]. Moreover, not only the pancreatic sPLA2 but also the pulmonary isoforms of the enzyme may be involved in the syndrome, [34] as lung sPLA2 production may be boosted by the meconium-induced release of pro-inflammatory cytokines [35-37] and through a specific cross-talk between different enzyme isoforms [38]. Consistently, we have recently found raised levels of pulmonary SPLA2 in BALF of patients affected by MAS when compared to their own meconium and to control babies [39]. MAS still has a mortality rate of about $50 \%$ and sometimes requires invasive treatments as broncho-alveolar lavage using saline/surfactant solutions or extra-corporeal life support [40,41].

sPLA2 is also involved in neonatal bile acids pneumonia, a more rare form of lung injury, [42] in which neonatal lungs are challenged with the bile acids coming from the maternal circulation when the mother is affected by obstetric cholestasis $[43,44]$. In this condition, the neonatal lung may experience a sPLA2 overactivation [33] due to the bile acids coming from maternal circulation. This may lead to severe respiratory failure, since bile acids increase the sPLA2 activity enabling the presentation of the phospholipid substrate to the catalytic site of the enzyme [45].

\section{sPLA2 genetics and human diseases}

It is known that some sPLA2 gene polymorphisms are associated with chronic obstructive pulmonary or coronary artery disease $[46,47]$. Given the wide role of sPLA2 in many critical respiratory conditions, an individual predisposition due to different polymorphisms is likely to exist. Nevertheless, data about sPLA2 genetics, its association with respiratory failure and its clinical severity have not been published.

\section{Methods and design}

\section{Study hypothesis and purposes}

Available data allow hypothesizing a role for sPLA2 or its modulators in the pathogenesis, in the clinical severity and in the development of complications of the above mentioned types of lung injury. Our aim is to clarify such role, in order to better understand whether or not sPLA2 therapeutic inhibition might be a helpful strategy. To do that, we are planning to:

1. Identify the exact subtype(s) of sPLA2 produced and secreted into the alveoli during post-neonatal ARDS-ALI, MAS, iRDS and IRRF. This is important to know because sPLA2 inhibitors may have a different specificity for the various enzyme subtypes. In animal models, distinct sPLA2 subtypes have been associated to lung dysfunction [1,48-50].

2. Study the main modulators of sPLA2 expression and activity (TNF $\alpha$, CCSP, SP-A and IL1). This will allow identification of possible pathway imbalances and eventually new therapeutic targets.

3. Clarify what happen to sPLA2 and its pathway when exogenous surfactant is administered, as it usually occurs to preterm neonates. This will allow to understand if there is a link between sPLA2 activity/overexpression, the repeated need for surfactant and BPD occurrence.

4. Clarify if there is a genetic predisposition due to different sPLA2 genes polymorphisms which could lead to more severe clinical pictures in iRDS, ARDS, MAS or IRRF or to a long term negative outcome.

\section{Originality of the project}

This is the first study aimed at investigating the whole sPLA2 pathway in the above-described types of lung injury. To date, no study has addressed the functioning of the whole sPLA2 pathway, including the role of genetics, pathway modulators and related exogenous therapies that may affect it. This is essential because the diseases in which sPLA2 is thought to be important are basically different and the enzyme could play a different role through different subtypes, with different influence of its modulators and various response to the exogenous surfactant administration. Moreover, gene polymorphisms may play a role affecting the enzyme activity and so the clinical picture. Furthermore, many respiratory diseases potentially caused or influenced by sPLA2 are typical of newborn infants (e. g.: MAS, iRDS) or are present both in adults and in children, but with different causes and characteristics (e.g.: ARDS) [51]. Thus, data coming from animal studies or from adult experience cannot be directly applied to children and a specific study is warranted. The data coming from the present project will be crucial for future studies targeted at developing an antisPLA2 therapeutics.

\section{Project management}

A multicenter design has been previewed and the project will be coordinated at the Laboratory of Clinical Molecular Biology of the University Hospital " $A$. Gemelli“, Catholic University of the Sacred Heart in Rome. A Study group on Secretory Phospholipase in Paediatrics (SSPP) has been arranged and project coordinators will be a clinical pathologist/biochemist (Prof. E. Capoluongo, Head of the Lab) and a paediatric intensivist/neonatologist (Dr. D. De Luca). 
SSPP will consist of two working groups for this project:

a. Laboratory group. This consists of biochemists and biologists experts in several molecular biology techniques applied to BALF specimens. These investigators will remain blinded to the clinical data, which will be known only to the project coordinators.

b. Clinical group. This will consists of all clinicians - neonatologists and/or pediatric intensivists - working in intensive care units (at the University Hospital "A.Gemelli" or in so called "Collaborating centers") where patients' enrolment, samples and data collection will be performed.

Clinical investigators will meet a project coordinator regularly before the beginning of the study. This will happen by tele-conference or by visiting the collaborating centre. All investigators will remain in contact during the entire project by e-mail and/or tele-conference. One of the project coordinator will also give a $24 \mathrm{~h} / 7 \mathrm{~d}$ availability by phone in case of urgent matters.

The project is still open and other intensive care units are welcomed to participate as collaborating centres. Interested colleagues should contact the corresponding author to discuss the study feasibility (please see at the end of manuscript).

\section{Study phases}

To accomplish the study purposes, the work will be subdivided in two phases:

1) clinical phase; 2) bench phase.

\section{1) clinical phase}

Enrolment The following group of patients will be identified: iRDS, IRRF, MAS, ARDS-ALI. To be enrolled in a group babies must fulfil all the following inclusion criteria:

A. Preterm neonates (gestational age $\leq 37$ sett) with iRDS

$C$-Reactive protein $(C R P)<10 \mathrm{mg} / \mathrm{L}$ or procalcitonin $(P C T)<0.6 \mathrm{ng} / \mathrm{mL}$ in the first 72 hours of life; Chest-Xrays typical for iRDS; no clinical signs of sepsis; need for mechanical ventilation.

B. Infants and neonates with IRRF (regardless of the age)

B1. Early IRRF. Neonates from mother with vaginal or urine positive cultures. Respiratory distress signs and $C R P>10 \mathrm{mg} / \mathrm{L}$ [52] or PCT $>0.6 \mathrm{ng} / \mathrm{mL}$ [53]in the first 72 hours of life; clinical signs of sepsis or blood/BALF positive culture; need for mechanical ventilation.

B2. Late IRRF. Neonates with respiratory distress signs beyond the first 72 hours of life or infants, irrespectively of the age and $C R P>10 \mathrm{mg} / \mathrm{L}[52]$ or $P C T>0.6 \mathrm{ng} / \mathrm{mL}$ [53]; clinical signs of sepsis or blood/BALF positive culture; need for mechanical ventilation.

\section{Neonates with MAS}

Neonates with meconium stained and thick amniotic fluid who required broncho-aspiration following Neonatal Resuscitation Program guidelines[54]. Continuous need for mechanical ventilation at 15 minutes of life. Chest- $X$ rays typical for MAS.

D. Infants with ARDS-ALI [55]

Infants beyond neonatal age ( $>30$ days of life) and $<1$ year of age under mechanical ventilation and having $\mathrm{PaO}_{2} / \mathrm{FiO}_{2}$ ratio $<200$ (ARDS) or < 300 (ALI), chest-X rays typical for ARDS-ALI, acute onset of the respiratory distress and no cardiogenic oedema/increase in left atrial pressure.

A control group has also been previewed, as follows:

E. Infants and neonates without respiratory diseases (NLD: No lung disease)

Patients ventilated for non-pulmonary reasons (e.g.: anaesthesia, central nervous system diseases), $\mathrm{PaO}_{2} / \mathrm{FiO}_{2}$ ratio $>300$ or $\mathrm{FiO}_{2}=0.21$, negative CRP and PCT, normal chest- $X$ rays and chest clinical examination.

A careful revision of the clinical characteristics will be done for each patient at the moment of discharge (or death). This will be done in each centre to ensure the appropriateness of diagnosis and internal validity.

Procedures to be performed in the intensive care units 1. Broncho-alveolar lavage.

This procedure will be performed as soon as possible from the fulfilling of the enrolment criteria. In case of neonates, broncho-alveolar lavage will be performed in the following schedule:

\section{- PRE-SURFACTANT}

- POST-SURFACTANT (after at least 12 hours from the surfactant administration)

- PRE-2 ${ }^{\text {nd }}$ SURFACTANT (only for babies needing a second dose)

- POST-SURFACTANT (after at least 12 hours from the $2^{\text {nd }}$ surfactant administration)

Obviously, for infants receiving just a single surfactant dose or no surfactant at all, only one or two bronchoalveolar lavages will be carried out.

This procedure is to be intended a non-bronchoscopic lavage: it will be performed according to our previously described and well standardized technique [15] and following the advices of the European Respiratory Society guidelines [56]. All BALF specimens will be added with $0.9 \%$ saline up to $2 \mathrm{~mL}$ and a small aliquot of the fluids will be sent for microbiological culture.

2. $1.5 \mathrm{~mL}$ blood drawing in a vial with no anti-coagulant to be centrifuged (see below). 
If a baby undergoes repeated broncho-alveolar lavages, the blood drawing will be repeated each time. Every BALF and blood specimens must be obtained within 1 hour from each other.

3. $0.5 \mathrm{~mL}$ blood drawing into an EDTA vial to be immediately stored at $4{ }^{\circ} \mathrm{C}$. This blood will be used for DNA extraction to analyse sPLA2 genes polymorphisms and will be drawn only once for each baby.

In general, blood drawings will be performed from an indwelling arterial line or from a central venous line to avoid haemolysis. Blood without anti-coagulant and BALF samples will be immediately centrifuged at 3000 rpm for 10 minutes to separate the serum or the supernatants which will be immediately stored at $-80^{\circ} \mathrm{C}$.

Data to be registered in the intensive care units The following data will be recorded either from the vital parameters monitors, from the ventilator screen or the clinical files.

- Name and sex

- Group of enrolment

- Type of ARDS (direct/indirect)

- Main identifiable cause of ARDS

- Pre-existing respiratory diseases (if any)

- Hours of life or hour from the fulfilment of enrolment criteria at which the samples have been obtained.

- Cumulative dose of prenatal steroids (for preterm neonates)

- Doses of steroids received till the enrolment (if any)

- Type of mechanical ventilation provided

- Peak inspiratory pressure, positive end-expiratory pressure, mean airway pressure (Pāw), Expired tidal volume (pro Kg)

- Total respiratory rate and spontaneous respiratory rate (if any)

- Dynamic compliance over ten mechanical breaths or static compliance using end-expiratory occlusion (depending on the ventilator) $^{\S}$

- Total respiratory system resistances over ten mechanical breaths

(If patients are ventilated with high frequency oscillatory ventilation, instead of the above-mentioned parameters, Pāw, amplitude and frequency will be recorded. If a specific flow-sensor [57] is available the tidal volume delivered during oscillations will also be registered and used for further calculation [see below]).

- Cumulative dose of exogenous surfactant (for neonates)

- $\mathrm{FiO}_{2}$

- Oxygen saturation at the right hand
- Gestational age/Birth weight or Age in months/ weight

- $\mathrm{PaCO}_{2}$ and $\mathrm{PaO}_{2}$

- $\mathrm{pH}$

- Base excess and Lactate

- Mean arterial pressure

- Central venous pressure (if available)

- Heart rate

- Blood urea nitrogen

These data must be recorded as close as possible to the broncho-alveolar lavage/blood drawing ( $\max$ within 1 hour from such procedures). These data will be recorded in real time in an appropriate electronic database provided by the coordinating centre to each intensive care unit participating in the study.

Moreover, using the above-mentioned data, the following indexes will be calculated:

- Oxygenation index $\left(\mathrm{FiO}_{2} \times \mathrm{Pa} w / \mathrm{PaO}_{2}\right)$

- $\mathrm{PaO}_{2} / \mathrm{FiO}_{2}$ ratio

- Ventilatory index (Peak - end expiratory pressure) $\times$ respiratory rate $\times \mathrm{PaCO}_{2} / 1000$ (if conventional ventilation is provided)

- Alveolar ventilation estimate during high frequency oscillatory ventilation $\left(\mathrm{DCO}_{2}=\right.$ frequency * (tidal volume $)^{2}$ ], if a specific flow sensor is available) [58]

Moreover, the following data will be recorded:

- Mortality

- Intensive care unit length of stay

- Duration of invasive ventilation

- Duration of oxygen therapy

- Any neurological sequel at the discharge

- Oxygen requirement after discharge

- Diagnosis of chronic lung disease, for preterm neonates, according to the NICHD definition of BPD [59].

Exclusion criteria Patients with one of the following characteristics will not be enrolled in any group:

1. Congenital lung malformations of any type

2. Lung or thoracic surgery

3. Lung cancer of any type

4. Congenital complex malformations

5. Patients undergoing extracorporeal life support.

Storage and transfer of data and samples All data will be anonymously stored in the above described electronic database and will remain property of the enrolling centre. At the end of the clinical phase they will be checked for validity in each centres and then sent in a secured 
way to the Coordinating centre. At that time all specimens will be also sent under dry ice to the Coordinating centre.

\section{2) Bench phase}

sPLA2 pathway In serum and BALF supernatants the following analyses will be performed:

- Western blotting for sPLA2-IIA, -V, -X. For this procedure external (actinin) and internal (recombinant human sPLA2 subtypes, -IIA, - V, -X) controls will be used and total protein measurements will also be performed with Bradford's method [5].

- TNFa assay

- SP-A assay

- IL1 assay

These assays will be performed using specific ELISA/ EIA kits already used to analyse BALF. These methods have been proven to do not cross-react with other cytokines and with sPLA2; in previous studies, coefficients of variation of the standard curve resulted always $\leq 9 \%[15,39,60-62]$.

- sPLA2 global activity assay

To do this assay, all samples will be centrifuged (for $10^{\prime}$ at $12000 \mathrm{rpm}$ and then for 3' at $3500 \mathrm{rpm}$ ) through a membrane-filter with a molecular weight cut-off of 30 kDa (Amicon Ultra centrifugal filter; Millipore, Billera, MA-USA), to separate the secretory and cytosolic phospholipases (which weight $\approx 14 \mathrm{kDa}$ and $\approx 80 \mathrm{kDa}$, respectively) $[39,62,63]$.

- High sensitivity urea nitrogen assay in the BALF supernatant.

All measurements in BALF will be corrected for the serum-to-BALF urea ratio, as previously described [64]. sPLA2 genetics sPLA2-IIA [HGNC:9031], -V [HGNC:9038] and -X [HGNC:9029] genes polymorphisms will be studied in the patients' leukocytes. We found 15 single nucleotide polymorphisms (SNP) for these genes. These polymorphisms were searched in the dbSNP (http://www.ncbi.nlm.nih.gov/SNP/), JSNP (http://snp.ims.u-tokyo.ac.jp), GenBank at the NCBI (http://www.genbank.com) and Applied Biosystems genotyping databases (http://www.appliedbiosystems.com), as well as in a previous study linking them to coronary artery disease [47]. Analysis of genetic polymorphisms SNP genotyping will be performed by TaqMan allelic discrimination assay [65]. Polymerase chain reaction will be performed with specific primers at concentrations of $900 \mathrm{nM}$. Fluorescence data files from each plate were analyzed by a specific software. In order to verify the correct genotype assignment, we will randomly analyse some of the above screened samples by means of genetic sequencing (BigDye terminator technique).

All laboratory procedures will be carried out respecting safety regulations and bench investigators will be blinded to the patients' group of origin and to their clinical data. To accomplish this blindness, before starting the bench phase all vials will be re-labelled with a new code and only the project coordinators will be aware of the new code.

Statistics and sample size Data will be tested for normality and then analyzed with parametric or non-parametric procedures, as appropriate. Accordingly, univariate analysis using Student and analysis of variance or Mann-Whitney, Wilcoxon, Kruskal-Wallis and Friedman tests will be performed. Some laboratory data will be subjected to correlation analysis with clinical findings, using Pearson's, Spearman's or Kendall's technique, according to data characteristics.

Subsequently, if needed, significant results will be subjected to multiple curve estimation procedure [66] and/ or multivariate analysis according to data characteristics and the results of the univariate analyses. The genetic data will be analyzed using $\chi^{2}$ test for the Hardy-Weinberg equilibrium of alleles at the individual loci. The association between genotypes and clinical data will be tested with $\chi^{2}$ - or Fisher test and then with logistic regression or analysis of co-variance, as appropriate [67]. All statistical analyses will be performed by the project coordinators, who have a long experience and formal training in biostatistics.

Despite a formal sample size calculation is not warranted, based on the available data $[5,11,19]$, we previewed a convenience sample size, as follows: 50-60 preterm infants affected by iRDS, with at least 20 receiving a second surfactant dose; for ARDS and IRRF groups 20 patients will be also convenient, while 10 control neonates or infants will be considered. These sample size have been checked for power regarding the correlation between sPLA2 activity and two selected clinical variables (using Power and Precision demo rel. 3.2 [68]). Given $\alpha$-error of 0.05 and a correlation coefficient $(r) \geq 0.6$ and $\geq 0.85[5,11,19]$ for the respiratory compliance and the $\mathrm{PaO}_{2} / \mathrm{FiO}_{2}$ ratio, respectively, the power resulted $>80 \%$ in both cases.

The study is supposed to last 12-18 months for the enrolment phase in each collaborating centre, and 3-6 months for the laboratory phase at the coordinating centre.

\section{Ethical considerations}

The protocol and consent form have been approved by the Ethical Committee of the University Hospital " $A$. Gemelli" at the Catholic University of the Sacred Heart 
(Rome, Italy) as coordinating centre. Local ethical boards in each collaborating centre have also approved the protocol.

The participation to the study will not change in any way the routine clinical assistance previewed for every patient. Furthermore, the participation to the study will respect all the local Regulations about safety procedures and the privacy. Informed consent will be given by parents or tutors of each baby, before the enrolment in the study.

\section{Publication policy}

Study results will be presented to each investigator by teleconference and/or e-mail. If possible a meeting in occasion of one of the major congresses in the field of Paediatrics or Critical Care (like the European Society for Paediatric Research or European Society for Paediatric and Neonatal Intensive Care Congresses) will be organised. Data will be also presented at these meetings and the subsequent manuscripts will be circulated between all investigators for revision. All resulting manuscripts will be authored by the project coordinators and by the group authorship (SSPP: Study group on Secretory Phospholipase in Paediatrics).

\section{Discussion}

This study, thanks to its multicenter design, will clarify the role(s) of sPLA2 and its pathway modulators in several paediatric and neonatal forms of lung injury. In fact, enough evidence is available to indicate sPLA2, or at least some of its subtypes, as a key point in the pathophysiology of certain critical respiratory diseases. Inflammation is a complex process and is essential in many of these conditions: sPLA2 might be the main crossroad between inflammation and surfactant catabolism. Since this latter is surely an important component of some clinical situations, sPLA2 is worth to be studied in its metabolic and genetic issues, trying to correlate them to the clinical pictures.

Given the peculiarity of such diseases and the relative rarity of some of them, only a multicentre design will be able to clarify this field. The purpose is not free from practical consequences, as several sPLA2 inhibitors are now available or under advanced development [69]. Many drugs are already used in respiratory critical care [70] but sPLA2 blockade might represent a new antiinflammatory therapy and a novel approach to protect surfactant or spare it, improving alveolar stability, lung mechanics and gas exchange.

The establishment of a net of centres involved in clinical research, along with the support of bench investigators, will help in understanding this field and in building future randomised interventional studies.

\section{Footnote}

${ }^{\$}$ Compliance measurement depends on the type of ventilator. Those with the end-expiratory occlusion will provide a static measure, otherwise a dynamic measurement will be done using the hot-wire anemometer flow sensor. In that case, to increase the measurement accuracy, the spontaneous breathing must be temporarily avoided, gas leaks must be $<5 \%$ and stable respiratory conditions with minimal airway secretions must be achieved. Conditions and technique for this measurement have been described in details elsewhere [15].

\section{List of abbreviations}

SPLA2: secretory phospholipase A2; CCSP: Clara cell secretory protein; SP-A: Surfactant protein A; ARDS: acute respiratory distress syndrome; ALI: acute lung injury; BALF: broncho-alveolar lavage fluids; iRDS: infant respiratory distress syndrome or hyaline membrane disease; BPD: broncho-pulmonary dysplasia; MAS: meconium aspiration syndrome; IRRF: infection related respiratory failure; RSV: respiratory sincytial virus; SSPP: Study group on Secretory Phospholipase in Pediatrics; CRP: C-Reactive protein; PCT: procalcitonin; Pāw: mean airway pressure; $\mathrm{DCO}_{2}$ : Alveolar ventilation estimation during high frequency oscillatory ventilation; CPLA2: cytosolic phospholipase; SNP: single nucleotide polymorphisms.

\section{Acknowledgements: Members of the SSPP Group}

For the present project the SSPP group is composed as follows (at Nov, 15 2010):

Project coordinators: D. De Luca, E. Capoluongo (Roma, Italy). Laboratory group: A. Minucci, F. Vendittelli, D. Tripodi, L. Gentile, C. Zuppi, B. Giardina (Roma, Italy).

Clinical group: M. Antonelli, G. Conti, D. Pietrini, M. Piastra (Roma, Italy), F. Cools, F. Camfferman (Bruxelles, Belgium), V. Rigo (Liège, Belgium), JT. Carbajosa, A. Remesal, L. Sanfeliciano, M.F. Benito Zaballos (Salamanca, Spain).

The project is still open and other intensive care units are welcomed to participate as collaborating centres. Colleagues interested in this should contact the project coordinator and corresponding author (D. De Luca: $\mathrm{dm}$. deluca@fastwebnet.it) to discuss the feasibility of the study in their local setting and the possibility to participate.

Fundings

The study has received funds by Catholic University of the Sacred Heart (part of Research fundings D1-2011, to E.Capoluongo) and by a charity program of a private engineering company (QProgetti srl, Rome, Italy, funds 2011), which has nothing to do with this research field and will have no role at all in the project.

\section{Author details}

'Pediatric Intensive Care Unit, Dept of Emergency and Intensive Care, University Hospital "A.Gemelli", Catholic University of the Sacred Heart Rome, Italy. ${ }^{2}$ Laboratory of Clinical Molecular Biology, Dept of Molecular Medicine, University Hospital "A.Gemelli", Catholic University of the Sacred Heart - Rome, Italy. ${ }^{3}$ Neonatal Intensive Care Unit, University of Liège, CHU de Liège (CHR Citadelle), Belgium.

\section{Authors' contributions}

DDL conceived the study design, created the multicentre network and visited the collaborating centres; he prepared the clinical phase, previewed the statistical analysis and drafted the manuscript. VR supervised the study design, helped in the creation of the multicentre net and drafted the manuscript. EC supervised the study design, identified the laboratory technique and the bench working program and drafted the manuscript. All members of the SSPP, contributed to the design of the study, discussed its practicability and provided what was needed to start the study in each centre, they all revised and approved the project and the final manuscript. 


\section{Competing interests}

The authors declare that they have no competing interest.

Received: 22 December 2010 Accepted: 8 November 2011

Published: 8 November 2011

\section{References}

1. Kitsiouli E, Nakos G, Lekka ME: Phospholipase A2 subclasses in acute respiratory distress syndrome. Biochim Biophys Acta 2009, 1792:941-53.

2. Dennis EA: The growing phospholipase A2 superfamily of signal transduction enzymes. Trends Biochem Sci 1997, 22:1-2.

3. Triggiani M, Giannattasio G, Calabrese C, Loffredo S, Granata F, Fiorello A, Santini M, Gelb MH, Marone G: Lung mast cells are a source of secreted phospholipases A2. J Allergy Clin Immunol 2009, 124:558-565.

4. Touqui L, Arbibe L: A role for phospholipase A2 in ARDS pathogenesis. Mol Med Tod 1999, 5:244-249.

5. Nakos G, Kitsiouli E, Hatzidaki E, Koulouras V, Touqui L, Lekka ME: Phospholipases A2 and platelet activating-factor acetylhydrolase in patients with acute respiratory distress syndrome. Crit Care Med 2005, 33:772-779.

6. Wheeler DS: Phospholipases A2 and acute lung injury: it's just not that simple. Crit Care Med 2005, 33:904-5.

7. Berger A, Havet N, Vial D, Arbibe L, Dumarey C, Watson ML, Touqui L: Dioleylphosphatidylglicerol inhibits the expression of type II phospholiase A2 in macrophages. Am J Resp Crit Care Med 1999, 159:613-619.

8. Furue S, Kuwabara K, Mikawa K, Nishina K, Shiga M, Maekawa N, Ueno M, Chikazawa Y, Ono T, Hori Y, Matsukawa A, Yoshinaga M, Obara H: Crucial role for group II-phospholipase A2 in oleic acid-induced acute lung injury in rabbits. Am J Resp Crit Care Med 1999, 160:1292-1302.

9. Granata F, Frattini A, Loffredo S, Del Prete A, Sozzani S, Marone G, Triggiani M: Signaling events involved in cytokines and chemokines production induced by secretory phospholipase A2 in human lung macrophages. Eur J Immunol 2006, 36:1938-1950.

10. Kim DK, Fukuda T, Thompson BT, Cockrill B, Hales C, Bonventre JV: Bronchoalveolar lavage fluid phospholipase A2 activities are increased in human adult respiratory distress syndrome. Am J Physiol 1995, 269: L109-18.

11. De Luca D, Minucci A, Cogo P, Capoluongo ED, Conti G, Pietrini D, Carnielli VP, Piastra M: Secretory phospholipase A2 pathway during pediatric acute respiratory distress syndrome: A preliminary study. Pediatr Crit Care Med 2011, 12:e20-4.

12. Liu T, Zaman W, Kaphalia BS, Ansari GA, Garofalo RP, Casola A: RSV induced prostaglandin E2 production occurs via CPLA2 activation: Role in viral replication. Virology 2005, 343:12-24.

13. Wang SZ, Rosenberger CL, Bao YX, Stark JM, Harrod KS: Clara Cell secretory proteein modulates inflammatory and immune responses to respiratory syncitial virus infection. J Immunol 2003, 171:1051-60.

14. Furue S, Mikawa K, Nishina K, Shiga M, Ueno M, Tomita Y, Kuwabara K, Teshirogi I, Ono T, Hori Y, Matsukawa A, Yoshinaga M, Obara H: Therapeutic time-window of a group IIA-phospholipase A2 inhibitor in rabbit acute lung injury: correlation with lung surfactant protection. Crit Care Med 2001, 29:719-727.

15. De Luca D, Minucci A, Trias J, Tripodi D, Conti G, Zuppi C, Capoluongo E: Varespladib Inhibits Secretory Phospholipase A2 in Bronchoalveolar Lavage of Different Types of Neonatal Lung Injury. J Clin Pharmacol 2011.

16. Zecca E, De Luca D, Costa S, Marras M, Romagnoli C: Neonatal Intensive Care and outcomes of extremely preterm infants: changes over a decade. Ital J Pediatr 2006, 32:48-54

17. Van Marter L: Epidemiology of bronchopulmonary dysplasia. Semin Fetal Neonatal Med 2009, 14:358-66.

18. Speer CP: Chorioamnionitis, postnatal factors and proinflammatory response in the pathogenetic sequence of bronchopulmonary dysplasia. Neonatology 2009, 95:353-61.

19. De Luca D, Baroni S, Vento G, Piastra M, Pietrini D, Romitelli F, Capoluongo E, Romagnoli C, Conti G, Zecca E: Secretory phospholipase A2 and neonatal respiratory distress. Pilot study on broncho-alveolar lavage. Intensive Care Med 2008, 34:1858-64.

20. Schrama AJJ, Elferink JGR, Hack CE, de Beaufort AJ, Berger HM, Walther FS: Pulmonary secretory phospholipase A2 in infants with respiratory distress syndrome stimulates in vitro neutrophil migration. Neonatology 2010, 97:1-9.

21. Levine CR, Gewolb IH, Allen K, Welch RW, Melby JM, Pollack S, Shaffer T, Pilon AL, Davis JM: The safety, pharmacokinetics, and anti-inflammatory effects of intratracheal recombinant human Clara cell protein in premature infants with respiratory distress syndrome. Pediatr Res 2005, 58:15-21.

22. Welty SE: CC10 administration to premature infants: in search of the "silver bullet" to prevent lung inflammation. Pediatr Res 2005, 58:7-9.

23. Chandra S, Davis JM, Drexler S, Kowalewska J, Chester D, Koo HC, Pollack S, Welch R, Pilon A, Levine CR: Safety and efficacy of intratracheal recombinant human Clara cell protein in a newborn piglet model of acute lung injury. Pediatr Res 2003, 54:509-515.

24. Angert RM, Pilon AL, Chester D, Davis JM: CC10 reduces inflammation in meconium aspiration syndrome in newborn piglets. Pediatr Res 2007, 62:684-688.

25. Shashikant BN, Miller TL, Welch RW, Pilon AL, Shaffer TH, Wolfson MR: Dose response to rhCC10-augmented surfactant therapy in a lamb model of infant respiratory distress syndrome: physiological, inflammatory, and kinetic profiles. J Appl Physiol 2005, 99:2204-11.

26. Yeh TF, Lin HC, Chang C, Wu TS, Su BH, Li TC, Pyati S, Tsai CH: Early intratracheal instillation of budesonide using surfactant as vehicle to prevent chronic lung disease in preterm infants: a pilot study. Pediatrics 2008, 121:e1310-1318.

27. Triggiani M, Granata F, Petraroli A, Loffredo S, Frattini A, Staiano Rl, Monaco G, Marone G: Inhibition of secretory phospholipase A2-induced cytokine production in human lung macrophages by budesonide. Int Arch Allergy Immunol 2009, 150:144-55.

28. Khammash H, Perlman M, Wojtulewicz J, Dunn M: Surfactant therapy in full-term neonates with severe respiratory failure. Pediatrics 1993, 92:135-139.

29. Herting E, Gefeller O, Land M, van Sonderen L, Harms K, Robertson B, Members of the Collaborative European Multicenter Study Group: Surfactant treatment of neonates with respiratory failure and group B streptococcal infection. Pediatrics 2000, 106:957-964.

30. Schrama AJJ, de Beaufort AJ, Sukul YR, Jansen SM, Poorthuis BJ, Berger HM: Phospholipase A2 is present in meconium and inhibits the activity of pulmonary surfactant: an in vitro study. Acta Paediatr 2001, 90:412-416.

31. Sippola T, Aho H, Peuravuori H, Lukkarinen H, Gunn J, Kaapa P: Pancreatic phospholipase A2 contributes to lung injury in experimental meconium aspiration. Pediatr Res 2006, 59:641-645.

32. Kaаpa P, Soukka H: Phospholipase A2 in meconium-induced lung injury. J Perinat 2008, 28:S120-S122.

33. De Luca D, Minucci A, Zecca E, Piastra M, Pietrini D, Carnielli VP, Zuppi C, Tridente A, Conti G, Capoluongo E: Bile acids cause secretory phospholipase A2 activity enhancement, revertible by exogenous surfactant administration. Intensive Care Med 2009, 35:321-6.

34. Korhonen K, Soukka H, Halkola L, Peuravuori H, Aho H, Pulkki K, Kero P, Kaapa PO: Meconium induces only localised inflammatory lung injury in piglets. Pediatr Res 2003, 54:192-7.

35. Salvesen B, Stenvik J, Rossetti C, Saugstad OD, Espevik T, Mollnes TE: Meconium-induced release of cytokines is mediatd by TLR4/MD2 complex in a CD14-dependent manner. Mol Immunol 2010, 47:1226-1234.

36. Granata F, Petraroli A, Boilard E, Bezzine S, Bollinger J, Del Vecchio L, Gelb MH, Lambeau G, Marone G, Triggiani M: Activation of cytokine production by secreted phospholipase A2 in human lung macrophages expressing the M-type receptor. J Immunol 2005, 174:464-474.

37. Vidyasagar $D$, Bhat $R$, Uhal $B$, Navale $S$, Zagariya A: TNFa, IL1 $\beta$, IL6, IL8, IFNY, PGE2 and IL10 expression in meconium aspirated newborn lungs [abstract]. Pediatr Res 1999, 45:325A.

38. Hurley BP, McCormick BA: Multiple roles of phospholipase A2 during lung infection and inflammation. Infect Immun 2008, 76:2259-72.

39. De Luca D, Minucci A, Tripodi D, Piastra M, Pietrini D, Zuppi C, Conti G, Carnielli VP, Capoluongo E: Role of distinct phospholipases A2 and their modulators in meconium aspiration syndrome in human neonates. Intensive Care Med 2011, 37:1158-65.

40. Brown KL, Sriram S, Ridout D, Cassidy J, Pandya H, Liddell M, Davis C, Goldman A, Field D, Karimova A: Extracorporeal membrane oxygenation and term neonatal respiratory failure deaths in the United Kingdom compared with the United States: 1999 to 2005. Pediatr Crit Care Med 2010, 11:60-5. 
41. Dargaville PA, Copnell B, Mills JF, Haron I, Lee JK, Tingay DG, Rohana J, Mildenhall LF, Jeng MJ, Narayanan A, Battin MR, Kuschel CA, Sadowsky JL, Patel H, Kilburn CJ, Carlin JB, Morley CJ, lessMAS Trial Study Group: Randomized controlled trial of lung lavage with dilute surfactant for meconium aspiration syndrome. J Pediatr 2011, 158:383-389.e2.

42. Zecca E, De Luca D, Baroni S, Vento G, Tiberi E, Romagnoli C: Bile acids induced lung injury: a broncho-alveolar lavage study. Pediatrics 2008, 121:e146-9.

43. Zecca E, De Luca D, Barbato G, Marras M, Tiberi E, Romagnoli C: Predicting respiratory distress syndrome in neonates from mothers with intrahepatic cholestasis of pregnancy. Early Hum Dev 2008, 84:337-41.

44. Zecca E, De Luca D, Marras M, Caruso A, Bernardini T, Romagnoli C: Intrahepatic cholestasis of pregnancy and neonatal respiratory distress syndrome. Pediatrics 2006, 117:1669-72.

45. Pan $\mathrm{YH}$, Bahnson BJ: Structural basis for bile salt inhibition of pancreatic phospholipase A2. J Mol Biol 2007, 369:439-50.

46. Takabatake N, Sata M, Inoue S, Shibata Y, Abe S, Wada T, Machiya J, Ji G, Matsuura T, Takeishi Y, Muramatsu M, Kubota I: A novel polymorphism in secretory phospholipase A2-IID is associated with body weight loss in chronic obstructive pulmonary disease. Am J Respir Crit Care Med 2005, 172:1097-104

47. Gora S, Perret C, Jemel I, Nicaud V, Lambeau G, Cambien F, Niuvo E, Blankenberg S, Tiret L, Karabuke SA: Molecular and functional characterization of polymorphisms in the secreted phopsholipase A2 group $\times$ gene: relevance to coronary artery disease. J Mol Med 2009, 87:723-733.

48. Ohtsuki M, Taketomi $Y$, Arata S, Masuda S, Ishikawa $Y$, Ishii T, Takanezawa $Y$, Aoki J, Arai H, Yamamoto K, Kudo I, Muratami M: Transgenic expression of group $V$ but not group $\times$ secreted phospholipase $A 2$ in mice leads to neonatal lethality because of lung dysfunction. J Biol Chem 2006, 281:36420-33

49. Muñoz NM, Meliton AY, Meliton LN, Dudek SM, Leff AR: Secretory group V phospholipase $A 2$ regulates acute lung injury and neutrophilic inflammation caused by LPS in mice. Am J Physiol Lung Cell Mol Physiol 2009, 296:L879-87.

50. Curfs DMJ, Ghesquiere SAI, Vergouwe MN, van der Made I, Gijbels MJJ, Greaves DR, Sjef Verbeek J, Hofker MH, de Winther MPJ: Macrophage Secretory Phospholipase A2 Group × Enhances Anti-inflammatory Responses, Promotes Lipid Accumulation, and Contributes to Aberrant Lung Pathology. J Biol Chem 2008, 283:21640-8.

51. Randolph AG: Management of acute lung injury and acute respiratory distress syndrome in children. Crit Care Med 2009, 37:2448-54.

52. Zecca E, Barone G, Corsello M, Romagnoli C, Tiberi E, Tirone C, Vento G: Reliability of two different bedside assays for C-reactive protein in newborn infants. Clin Chem Lab Med 2009, 47:1081-1084.

53. Jacquot A, Labaune JM, Baum TP, Putet G, Picaud JC: Rapid quantitative procalcitonin measurement to diagnose nosocomial infections in newborn infants. Arch Dis Child Fetal Neonatal Ed 2009, 94:F345-8.

54. American Heart Association American Academy of Pediatrics: 2005 American Heart Association guidelines for cardiopulmonary resuscitation and emergency cardiovascular care of pediatric and neonatal patients: neonatal resuscitation guidelines. Pediatrics 2006, 117:1029-1038.

55. Bernard GR, Artigas A, Brigham KL, Carlet J, Falke K, Hudson L, Lamy M, Legall JR, Morris A, Spragg R, the Consensus Committee: AmericanEuropean Consensus Conference on ARDS. Definition, mechanisms, relevant outcomes and clinical trial coordination. Am J Respir Crit Care Med 1994, 149:818-824.

56. European Respiratory Society Task Force on bronchoalveolar lavage in children: Bronchoalveolar lavage in children. Eur Respir J 2000, 15:217-231.

57. Scalfaro P, Pillow JJ, Sly PD, Cotting J: Reliable tidal volume estimates at the airway opening with an infant monitor during high-frequency oscillatory ventilation. Crit Care Med 2001, 29:1925-1930.

58. Chang HK: Mechanisms of gas transport during ventilation by high frequency oscillation. J Appl Physiol 1984, 56:553-564.

59. Jobe $\mathrm{AH}$, Bancalari E: Bronchopulmonary displasia. NICHD/NHLBI/ORD Workshop Summary. Am J Respir Crit Care Med 2001, 163:1723-1729.

60. Berdat P, Wehrle TJ, Küng A, Achermann F, Sutter M, Carrel TP, Nydegger UE: Age-specific analysis of normal cytokine levels in healthy infants. Clin Chem Lab Med 2003, 4:1335-1339.
61. Coppens JT, Van Winkle LS, Pinkerton KE, Plopper CG: Distribution of Clara Cell Secretory Protein expression in the tracheobronchial airways of rhesus monkeys. Am J Physiol Lung Cell Mol Physiol 2007, 292:1155-1162.

62. Reynolds LJ, Hughes LL, Dennis EA: Analysis of human synovial fluid phospholipase A2 on short chain phosphatidylcholine-mixed micelles: development of a spectrophotometric assay suitable for a microtiter plate reader. Anal Biochem 1992, 204:190-197.

63. Reynolds LJ, Hughes LL, Yu L, Dennis EA: 1-Hexadecyl-2-arachidonoylthio2-deoxy-sn-glycero-3-phosphorylcholine as a substrate for the microtiterplate assay of human cytosolic phospholipase A2. Anal Biochem 1994, 217:25-32

64. Capoluongo E, Ameglio F, Lulli P, Minucci A, Santonocito C, Concolino P, Di Stasio E, Boccacci S, Vendettuoli V, Giuratrabocchetta G, De Cunto A, Tana M, Romagnoli C, Zuppi C, Vento G: Epithelial lining fluid free IGF-Ito-PAPP-A ratio is associated with bronchopulmonary dysplasia in preterm infants. Am J Physiol Endocrinol Metab 2007, 292:E308-E313.

65. Livak KJ: Allelic discrimination using fluorogenic probes and the $5^{\prime}$ nuclease assay. Genet Anal 1999, 14:143-149.

66. Norusis M: SPSS 13.0 advanced statistical procedures companion. Prentice Hall: Upper Saddle-River; 2004.

67. Wildt AR, Ahtola OT: Analysis of covariance. In Quantitative Applications in the Social Sciences, series 12. Edited by: Hills, B. Thousand Oaks, CA: Sage Publications; 1978:

68. Dupont WD, Plummer WD Jr: Power and sample size calculations. A review and computer program. Control Clin Trials 1990, 11:116-28.

69. Garcia-Garcia HM, Serruys PW: Phospholipase A2 inhibitors. Curr Opin Lipidol 2009, 20:327-32

70. De Luca D, Cogo P, Zecca E, Piastra M, Pietrini D, Tridente A, Conti G, Carnielli VP: Intrapulmonary drug administration in neonatal and paediatric critical care: a comprehensive review. Eur Respir J 2011, 37:678-89.

\section{Pre-publication history}

The pre-publication history for this paper can be accessed here: http://www.biomedcentral.com/1471-2431/11/101/prepub

doi:10.1186/1471-2431-11-101

Cite this article as: De Luca et al:: Secretory phospholipase A2 pathway in various types of lung injury in neonates and infants: a multicentre translational study. BMC Pediatrics 2011 11:101.

\section{Submit your next manuscript to BioMed Central and take full advantage of:}

- Convenient online submission

- Thorough peer review

- No space constraints or color figure charges

- Immediate publication on acceptance

- Inclusion in PubMed, CAS, Scopus and Google Scholar

- Research which is freely available for redistribution

Submit your manuscript at www.biomedcentral.com/submit
C) Biomed Central 